\title{
Immunogenetics and the Pathological Mechanisms of Human T-Cell Leukemia Virus Type 1- (HTLV-1-)Associated Myelopathy/Tropical Spastic Paraparesis (HAM/TSP)
}

\begin{abstract}
Mineki Saito
Department of Immunology, Graduate School of Medicine, University of the Ryukyus, Uehara 207, Nishihara-cho, Nakagami-gun, Okinawa 903-0215, Japan

Correspondence should be addressed to Mineki Saito, mineki@med.u-ryukyu.ac.jp

Received 8 October 2009; Accepted 4 January 2010

Academic Editor: Marylou V. Solbrig

Copyright () 2010 Mineki Saito. This is an open access article distributed under the Creative Commons Attribution License, which permits unrestricted use, distribution, and reproduction in any medium, provided the original work is properly cited.

Human T-cell leukemia virus type 1 (HTLV-1) is a replication-competent human retrovirus associated with two distinct types of disease only in a minority of infected individuals: the malignancy known as adult T-cell leukemia (ATL) and a chronic inflammatory central nervous system disease HTLV-1-associated myelopathy/tropical spastic paraparesis (HAM/TSP). Although the factors that cause these different manifestations of HTLV-1 infection are not fully understood, accumulating evidence suggests that complex virus-host interactions play an important role in determining the risk of HAM/TSP. This review focuses on the role of the immune response in controlling or limiting viral persistence in HAM/TSP patients and the reason why some HTLV-1-infected people develop HAM/TSP whereas the majority remains asymptomatic carriers of the virus.
\end{abstract}

\section{Introduction}

Human T-cell leukemia virus type $1(\mathrm{HTLV}-1)$ infection is of particular interest to the field of immunology as well as microbiology because HTLV-1 is never eliminated from the host in spite of vigorous cellular and humoral immune responses against the virus but causes no disease in vast majority of infected subjects (asymptomatic carriers:ACs). Although only approximately $2 \%-3 \%$ develop adult $\mathrm{T}$ cell leukemia (ATL) $[1,2]$ and another $0.25 \%-3.8 \%$ develop chronic inflammatory diseases involving the central nervous system (HTLV-1-associated myelopathy/tropical spastic paraparesis: HAM/TSP) [3, 4], evaluation of the individual risk for developing diseases in each ACs would certainly be of considerable importance especially in HTLV-1 endemic area such as southern Japan, the Caribbean, Central and South America, the Middle East, Melanesia, and equatorial regions of Africa [5]. However, many fundamental questions are remained to be solved. First, how does HTLV-1 persist in the individual host in spite of strong host immune response? Second, why do some HTLV-1-infected people develop consequent diseases such as ATL or HAM/TSP, whereas the majority remains asymptomatic carriers of the virus? Third, how is the inflammatory lesion in HAM/TSP initiated and maintained, and why is the inflammation specifically in thoracic spinal cord? This review summarizes the past and recent works for HAM/TSP attempting to resolve each of these questions.

\section{Clinical and Pathological Features of HAM/TSP}

HTLV-1 is classified as a complex retrovirus in the genus Deltaretrovirus of the subfamily Orthoretrovirinae and infects 10-20 million people worldwide [6-8]. HTLV-1 can be transmitted through sexual contact [9], injection drug use [8], and breastfeeding from mother to child $[10,11]$. Although HTLV-1 infection is associated with a range of nonmalignant chronic inflammatory diseases in the eyes, the lungs, or the skeletal muscles [7], HAM/TSP is the bestrecognized with chronic progressive myelopathy characterized by spastic paraparesis, sphincter dysfunction, and mild sensory disturbance in the lower extremities [12]. To date, more 
than 3,000 cases of HAM/TSP patients have been reported in HTLV-1 endemic areas. Sporadic cases have also been described in nonendemic areas such as the United States and Europe, mainly in immigrants from an HTLV-1 endemic area. Among ACs, the lifetime risk of developing HAM/TSP, which is different among different ethnic groups, ranges between $0.25 \%$ and $4 \%$. It has been reported that the annual incidence of HAM/TSP is higher among Jamaican subjects than among Japanese subjects (20 versus 3 cases/100,000 population), with a two to three times higher risk for women in both populations [13-16].

Pathological analysis of HAM/TSP autopsy materials indicates that the disease affects the spinal cord, predominantly at the thoracic level [17-19]. Loss of myelin and axons in the lateral, anterior, and posterior columns is associated with perivascular and parenchymal lymphocytic infiltration with the presence of foamy macrophages, proliferation of astrocytes, and fibrillary gliosis. The presence of atypical lymphocytes (so-called "flower cells") in peripheral blood and cerebrospinal fluid (CSF), a moderate pleocytosis, and raised protein content in CSF are typically found in HAM/TSP patients. Oligoclonal bands, raised concentrations of inflammatory markers such as neopterin, tumor necrosis factor (TNF)- $\alpha$, interleukin (IL)- 6 and interferon (IFN) $-\gamma$, and an increased intrathecal antibody synthesis specific for HTLV-1 antigens have also been described [20]. Clinical progression of HAM/TSP is associated with increased proviral load in individual patients, and the ratio of proviral loads in CSF cells/in peripheral blood mononuclear cells (PBMCs) is significantly associated with clinically progressive disease [21]. The major histocompatibility complex (MHC) class I tetramer analysis of lymphocytes isolated from the CSF of HAM/TSP patients showed even higher frequencies of HTLV-1 Tax11-19-specific, HLA-A*02-restricted $\mathrm{CD}^{+}$lymphocytes compared to those of PBMCs [22]. Therefore, an increased proliferation or migration of HTLV1-infected and/or HTLV-1-specific lymphocytes to the central nervous system (CNS) might be closely associated with HAM/TSP pathogenesis [23].

\section{Risk Factors for HAM/TSP}

3.1. Host Genetics. Previous population association study of 202 cases of HAM/TSP and 243 ACs in Kagoshima, HTLV1 endemic southern Japan, revealed that one of the major risk factors is the HTLV-1 proviral load. The median proviral load was more than ten times higher in HAM/TSP patients than in ACs, and a high proviral load was also associated with an increased risk of progression to disease [24]. Higher proviral load in HAM/TSP patients than in ACs was observed in other endemic area, such as the Caribbean [25], South America [26], and the Middle East [27]. It was suggested that genetic factors such as human leukocyte antigen (HLA) are related to the high proviral load in HAM/TSP patients and genetic relatives. In southern Japan, possession of the HLA-class I genes HLA-A*02 and $\mathrm{Cw}^{*} 08$ was associated with a statistically significant reduction in both HTLV-1 proviral load and the risk of HAM/TSP, whereas possession of HLA-class I HLA-B* 5401 and class II HLA-DRB1*0101 predisposes to HAM/TSP in the same population [28, 29]. Since the function of class I HLA proteins is to present antigenic peptides to cytotoxic T lymphocytes (CTL), these results imply that individuals with $\mathrm{HLA}^{*} \mathrm{~A}^{*} 02$ or HLA$\mathrm{CW}^{*} 08$ mount a particularly efficient CTL response against HTLV-1, which may be an important determinant of HTLV1 proviral load and the risk of HAM/TSP. Further analysis to look at nonHLA host genetic factors revealed that nonHLA gene polymorphism also affects the risk for developing HAM/TSP. For example, the TNF- $\alpha$ promoter $-863 \mathrm{~A}$ allele [30], and the longer CA repeat alleles of matrix metalloproteinase (MMP)-9 promoter [31] predisposed to HAM/TSP, whereas IL-10 -592 A [32], Stromal derived factor (SDF)-1 +801A [30] and IL-15 +191 C alleles [30] conferred protection against HAM/TSP. The polymorphisms of MMP9 and IL-10 promoter each linked to the HTLV-1-encoded transactivator Tax-mediated transcriptional activity of each gene $[31,32]$.

3.2. HTLV-1 Genotype. Although most studies of HTLV-1 genotype have reported no association between variants of HTLV-1 and the risk of HAM/TSP, Furukawa et al. reported the association between HTLV-1 $\operatorname{tax}$ gene variation and the risk of HAM/TSP [33]. The tax subgroup A that belongs to cosmopolitan subtype A was more frequently observed in HAM/TSP patients and this effect was independent of protective allele HLA-A*02. HLA-A*02 appeared to give protection against only one of the two prevalent sequence variants of HTLV-1, tax subgroup B that belongs to cosmopolitan subtype B but not against tax subgroup $A$ in Japanese population [33]. Interestingly, HLA-A*02 appears not to give protection against infection with cosmopolitan subtype A in a population in Iran [27]. These findings suggest that both host genetic factors and HTLV-1 subgroup play a part in determining the risk of HAM/TSP.

\section{The Immune Response to HTLV-1}

4.1. The Humoral Immune Response. In HTLV-1 infection, anti-HTLV-1 antibody that often includes IgM is detected in all infected individuals, either ACs or patients with HAM/TSP [34]. It has been reported that HAM/TSP patients generally had higher anti-HTLV-1 antibody titer than ACs with the similar HTLV-1 proviral load [34-36]. These data suggest that there was persistent expression of HTLV-1 proteins in vivo and the existence of an augmented humoral immune response to HTLV-1 in HAM/TSP patients. Interestingly, although antibody responses to the immunodominant epitopes of the HTLV-1 Envelope (Env) proteins were similar in all of three clinical groups (HAM/TSP, ATL, and ACs), reactivity to four Tax immunodominant epitopes was highest in HAM/TSP $(71 \%-93 \%)$ than ATL patients $(4 \%-31 \%)$ or ACs $(27 \%-37 \%)$ [37]. In 2002, Levin et al. reported that antibodies that recognize HTLV-1 Tax protein can crossreact with a heterogenous nuclear riboprotein (hnRNP)-A1, suggesting intriguing evidence for antigen mimicry in HTLV1 infection [38]. However, since the host protein hnRNP-A1 is not confined to the central nervous system but is widely expressed [39] and is not normally accessible to antibody 
attack, it is unlikely that anti-Tax antibody explains the onset or initial tissue damage of HAM/TSP. Rather, anti-Tax antibody might be associated with subsequent inflammation following initial tissue damage and disruption of blood brain barrier, which is probably caused by the antiviral immune responses to HTLV-1 and induces the release of autoantigens.

4.2. The Natural Killer (NK) Cell Response. Previous reports indicated that patients with HAM/TSP had both a lower frequency and a lower activity of NK cells (especially the $\mathrm{CD}^{+}{ }^{+} \mathrm{CD} 16^{+}$subset) than ACs, although the results were not normalized with respect to the proviral load [40]. Since an important mechanism of induction of NK cell-mediated killing is recognition by the NK cell of a complex of the nonpolymorphic MHC molecule HLA-E bound to a peptide derived from the signal sequence of some other MHC class I molecules, the synthetic tetramers of HLA-E with the HLA-G signal sequence peptide were used to identify NK cells in HAM/TSP patients [41]. The results clearly showed a lower frequency of HLA-E tetramer-binding cells in HAM/TSP patients than ACs, and as in the earlier studies [40], this reduction in frequency was particularly notable in the $\mathrm{CD}^{+}$cells whereas there was no significant difference in the frequency of HLA-E tetramer-binding $\mathrm{CD}^{-}$cells between patients with HAM/TSP and ACs [41]. Recent data also suggest that the frequency of invariant NKT cells in the peripheral blood of HAM/TSP patients is significantly decreased when compared with healthy subjects and/or ACs $[42,43]$. These findings indicated that the activity of the NK or NKT cell response was associated with the presence or absence of HAM/TSP. Interestingly, previous uncontrolled preliminary trial of viable Lactobacillus casei strain Shirota containing fermented milk for HAM/TSP patients resulted in significant increase of NK cell activity with improvements in clinical symptoms [44]. Thus, circulating NK and NKT cells might also play an important role in the disease progression and the pathogenesis of HAM/TSP.

4.3. The Regulatory T Cells (Tregs). It has been reported that HTLV-1 preferentially and persistently infects $\mathrm{CD} 4{ }^{+} \mathrm{CD} 25^{+}$ lymphocytes in vivo [45], which contains the majority of the Foxp $3^{+}$Tregs [46]. In HAM/TSP patients, the percentage of Foxp $3^{+}$Tregs in $\mathrm{CD}^{+} \mathrm{CD} 25^{+}$cells is lower than that in ACs and uninfected healthy controls $[45,47]$ whereas the percentage of Foxp $3^{+}$cells in the $\mathrm{CD}^{+}$population tended to be higher in the HAM/TSP patients than in the ACs [4850]. As CD25 is induced by HTLV-1 Tax oncoprotein [51], it is most likely that the proportion of Foxp $3^{+}$cells falls in the $\mathrm{CD} 4{ }^{+} \mathrm{CD} 25^{+}$population, which contain both Tregs and activated nonTregs, in HTLV-1-infected individuals especially HAM/TSP patients. Interestingly, the frequency of HTLV-1 negative Foxp $3^{+} \mathrm{CD} 4^{+}$cells positively correlated with the HTLV-1 proviral load $[23,49]$ and the CTL activity negatively correlated with the frequency of HTLV-1 negative Foxp $3^{+} \mathrm{CD}^{+}$cells [49]. These data suggest that an increase in HTLV-1 negative FoxP3 ${ }^{+} \mathrm{CD}^{+}$Tregs is one of the chief determinants of the efficiency of $\mathrm{T}$ cell mediated immune control of HTLV-1. If such Tregs reduce CTL activity, which in turn increases the HTLV-1 proviral load, this activity increases the risk for developing HAM/TSP.

4.4. The $C D 4^{+}$Helper $T$ Cell Response. It is well known that antiviral $\mathrm{CD}^{+} \mathrm{T}$ cell responses are of central importance in driving $\mathrm{B}$-cell and $\mathrm{CD}^{+} \mathrm{T}$-cell responses in vivo. The HTLV-1 antigen most commonly recognized by $\mathrm{CD} 4^{+} \mathrm{T}$ cells is the Env protein [52, 53], in contrast with the immunodominance of Tax in the $\mathrm{CD}^{+} \mathrm{T}$ cell response [5456]. At a similar proviral load, patients with HAM/TSP had significantly increased frequency of virus-specific $\mathrm{CD} 4^{+} \mathrm{T}$ cells compared to that of ACs $[53,57]$. The antiviral $\mathrm{T}$ helper (Th) 1 phenotype is also dominant among HTLV1-specific $\mathrm{CD}^{+} \mathrm{T}$ cells in both ACs and patients with HAM/TSP [58], and there is a higher frequency of IFN- $\gamma$, TNF- $\alpha$, and IL- 2 production by $\mathrm{CD}^{+}{ }^{+} \mathrm{T}$ cells in patients with HAM/TSP compared to ACs of a similar proviral load $[58,59]$. A role for $\mathrm{CD} 4+\mathrm{T}$ cells in initiating and causing HAM/TSP is also consistent with the immunogenetic observations that the possession of HLA-DRB $1^{*} 0101$, which restricts immunodominant epitope of HTLV-1 Env gp21, was associated with susceptibility to HAM/TSP in independent HTLV-1-infected populations in southern Japan $[28,29]$ and northeastern Iran [27]. Accordingly, a synthetic tetramer of DRB1*0101 and the immunodominant HTLV-1 Env380-394 peptide was used to analyze Env-specific CD4 ${ }^{+}$ $\mathrm{T}$ cells directly ex vivo [57]. The results showed that the frequency of tetramer ${ }^{+} \mathrm{CD} 4^{+} \mathrm{T}$ cells was significantly higher in HAM/TSP patients than in ACs with similar proviral load. Moreover, direct ex vivo analysis of tetramer ${ }^{+} \mathrm{CD} 4^{+} \mathrm{T}$ cells from two unrelated DRB $1 * 0101$ positive HAM/TSP patients indicated that certain $\mathrm{T}$ cell receptor (TCR) $\mathrm{V} \beta$ s were utilized and antigen-specific amino acid motifs were identified in complementarity determining region (CDR) 3 from both patients. These data suggest that the observed increase in virus-specific $\mathrm{CD}^{+}{ }^{+} \mathrm{T}$ cells in HAM/TSP patients, which may contribute to $\mathrm{CD} 4^{+} \mathrm{T}$ cell-mediated antiviral immune responses and to an increased risk of HAM/TSP, was not simply due to the rapidly growing HTLV-1-infected CD4 ${ }^{+}$ $\mathrm{T}$ cells but was the result of in vivo selection by specific MHC-peptide complexes, as observed in freshly isolated HLA-A*0201/Tax11-19 tetramer ${ }^{+} \mathrm{CD}^{+}{ }^{+} \mathrm{T}$ cells [60] and muscle infiltrating cells from HAM/TSP patients and HTLV1-infected polymyositis patients [61].

4.5. The Cytotoxic T Lymphocyte (CTL) Response. Previous reports indicated that the HTLV-1-specific $\mathrm{CD}^{+}$CTL is typically abundant, chronically activated, and mainly targeted to the viral transactivator protein Tax [62]. Also, as already mentioned, the median proviral load in PBMCs of HAM/TSP patients was more than ten times higher than that in ACs, and a high proviral load was also associated with an increased risk of progression to disease [24]. Furthermore, HLA-A $* 2$ and HLA-Cw* 08 genes were independently and significantly associated with a lower proviral load and a lower risk of HAM/TSP $[28,29]$, and $\mathrm{CD}^{+}{ }^{+} \mathrm{T}$ cells efficiently kill autologous Tax-expressing lymphocytes in fresh PBMCs in HTLV-1-infected individuals [63]. These data have raised the hypothesis that the class I-restricted $\mathrm{CD}^{+}$CTL response 


\section{PBMCs}

Genetically determined differences in the efficiency of the CTL response to HTLV-1 $\downarrow$

Proliferation of infected cells Expression of HTLV-1 antigen $\downarrow$

Increase in activated $\mathrm{T}$ cells and organ infiltration

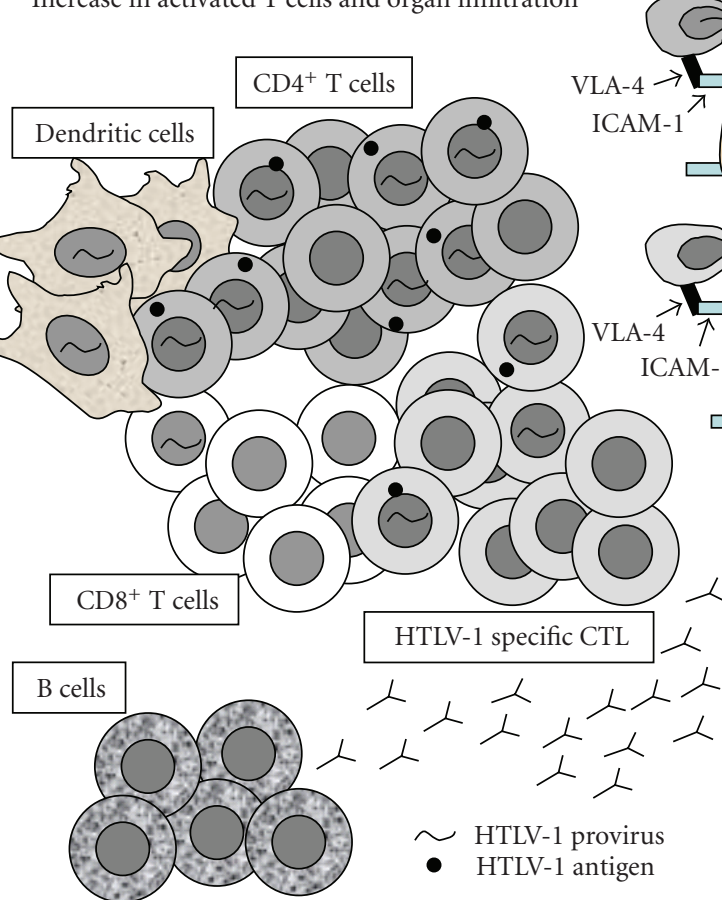

Blood brain barrier

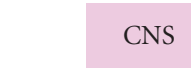

CNS

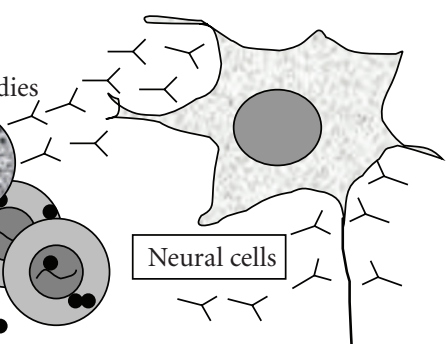

(1)

ti-Tax antibodies
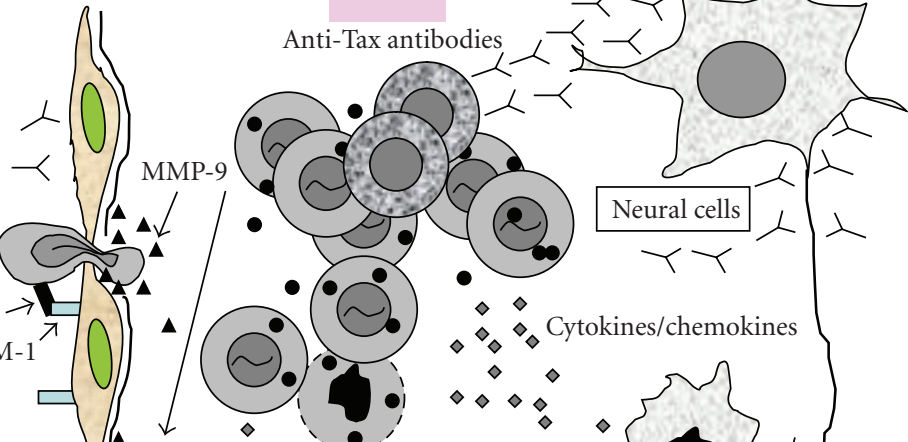

$\diamond \diamond$

$\diamond \diamond_{\diamond}$ Cytokines/chemokines

$\diamond \diamond \diamond \diamond$
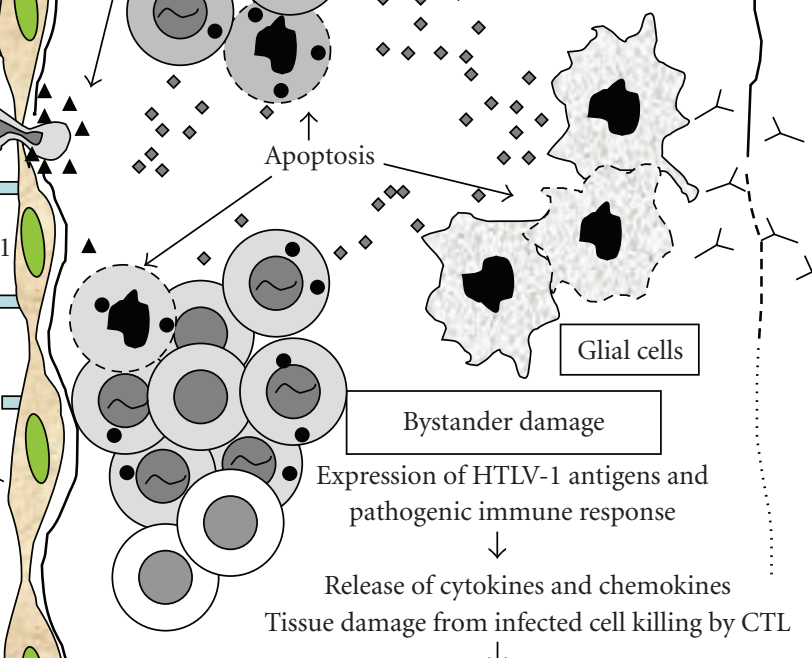

Tissue damage from infected cell killing by CTL
$\downarrow$

Induce inflammation

Further tissue damage mediated by anti-Tax antibody

that cross-react with cellular autoantigen

pathogenic immune response

$\downarrow$

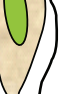

V

FIGURE 1: Hypothesis for the pathogenesis of Human T-cell leukemia virus type 1- (HTLV-1-)associated myelopathy/tropical spastic paraparesis (HAM/TSP). In patients with HAM/TSP, genetically determined less efficient CTL response against HTLV-1 may cause higher proviral load and antigen expression, leading in turn to activation and expansion of antigen-specific $\mathrm{T}$ cell responses, subsequent induction of large amounts of proinflammatory cytokines and chemokines, and progression of HAM/TSP development. It is also possible that the immunoglobulin G specific to HTLV-1-Tax, which cross-reacts with heterogeneous nuclear ribonuclear protein-A1 (hnRNP-A1), is associated with subsequent inflammation following initial tissue damage.

plays a critical part in limiting HTLV-1 replication in vivo and that genetically determined differences in the efficiency of the CTL response to HTLV-1 account for the risk for developing HAM/TSP. However, since the frequency of HTLV-1-specific CD8 ${ }^{+} \mathrm{T}$ cells was significantly elevated in HAM/TSP patients than in ACs $[64,65]$ and these cells have the potential to produce proinflammatory cytokines [66], there is a debate on the role of HTLV-1-specific-CD8 ${ }^{+} \mathrm{T}$ cells, that is, whether these cells contribute to the inflammatory and demyelinating processes of HAM/TSP or whether the dominant effect of such cells in vivo is protective against disease, although these two mechanisms are not mutually exclusive. Recently, Sabouri et al. reported that a frequency of $\mathrm{CD}^{+} \mathrm{T}$ cells that were negative for costimulatory molecules such as CD27, CD28, CD80, CD86, and CD152 was significantly higher in patients with HAM/TSP than in age-matched uninfected controls, but there was no such difference between ACs and uninfected controls [67]. They also found a significantly lower frequency of perforin ${ }^{+}$cells and granzyme $\mathrm{B}^{+}$cells in the $\mathrm{CD}^{+} \mathrm{T}$ cells in HTLV- 1-infected subjects than in uninfected controls, although there was no significant difference between patients with HAM/TSP and ACs. Furthermore, the lytic capacity of HTLV-1-specific CTL between HAM/TSP and ACs estimated by CD107a mobilization assay showed the significantly lower CD107a staining in HTLV-1-specific CTL in HAM/TSP than ACs. These findings suggest that patients with HAM/TSP have a high frequency of HTLV-1-specific $\mathrm{CD} 8^{+} \mathrm{T}$ cells with poor lytic capacity, whereas ACs has a lower frequency of cells with high lytic capacity.

4.6. Dendritic Cells (DCs). Dendritic cells are antigenpresenting cells which play a critical role in the regulation of the adaptive immune response. In HTLV-1 infection, it has been shown that the DCs from HAM/TSP patients were infected with HTLV-1 [68], and the development of HAM/TSP is associated with rapid maturation of DCs [69]. One of the hallmarks of HTLV-1 infection is the in vitro proliferation of PBMCs when cultured in the absence of exogenous antigen or mitogen, referred to as spontaneous 
lymphocyte proliferation (SLP), and in HAM/TSP patients, the levels of SLP reflect the severity of the disease [70, 71]. Interestingly, depletion of DCs from the HAM/TSP patient's PBMCs abolishes SPL while supplementing DCs, but not $B$ cells nor macrophages restore proliferation [68]. DC dependent mechanism of SLP was further supported by data showing that antibodies to MHC class II, CD86, and CD58 can block SPL [72]. Recently, Jones et al. had demonstrated that human-derived both myeloid and plasmacytoid DCs are susceptible to infection with cell-free HTLV-1, and HTLV1 -infected DCs can rapidly transfer virus to autologous primary $\mathrm{CD} 4^{+} \mathrm{T}$ cells [73]. Furthermore, in contrast to the previous report that $\mathrm{CD} 4^{+} \mathrm{CD} 25^{+} \mathrm{T}$ cells are responsible for the stimulation of Tax-specific $\mathrm{CD}^{+} \mathrm{T}$ cells [74], it was recently demonstrated that, compared to the $\mathrm{CD} 4^{+} \mathrm{CD} 25^{+}$ $\mathrm{T}$ cells, the DCs are the major cell type responsible for the generation and maintenance of the Tax-specific $\mathrm{CD} 8^{+} \mathrm{T}$ cells both in vitro and in vivo [75]. These findings suggest that the interaction of DCs with HTLV-1 is also crucial for the pathogenesis of HAM/TSP.

4.7. The Other Reservoirs of HTLV-1. Previous studies have indicated that only a small proportion of the monocytemacrophage lineage cells are infected with HTLV-1 in peripheral blood [76] and that there has been no direct evidence indicating that HTLV-1-infected cells of the monocytemacrophage lineage cells are present in the CNS [77]. However, monocyte-macrophage lineage cells may also play important roles in the pathogenesis of HAM/TSP, since it has been shown that the activation of macrophage and microglial cells within the CNS closely correlated with the proviral load within the CNS of HAM/TSP patients [78]. Meanwhile, it was also shown that a vast majority of bone marrow cells from HAM/TSP patients are positive for HTLV1 proviral DNA but negative for viral RNA expression [79], whereas no HTLV-1 proviral DNA positive CD34 hematopoietic progenitor cells were detected in ATL patients [80]. These results suggest that HTLV-1-infected cells within the bone marrow may be a reservoir of HTLV-1 in HAM/TSP patients and play an important role in the etiology of neuroinflammation observed in HAM/TSP [77].

\section{Conclusions}

As shown in Figure 1, accumulating evidence suggests that the virus-host immunologic interactions play a pivotal role in HAM/TSP pathogenesis. Genetically determined less efficient CTL response against HTLV-1 may cause higher proviral load and antigen expression in infected individuals, which lead to activation and expansion of antigen-specific $\mathrm{T}$ cell responses, subsequent induction of large amounts of proinflammatory cytokines and chemokines, and progression of HAM/TSP development.

\section{Acknowledgments}

The author thanks the Ministry of Health, Labor and Welfare, Japan (Health Labour Sciences Research Grant) and the Japan Society for the Promotion of Science (JSPS) (Grant-in-Aid for Scientific Research, ref 21590512) for financial supports.

\section{References}

[1] Y. Hinuma, Nagata, M. Hanaoka, et al., "Adult T-cell leukemia: antigen in an ATL cell line and detection of antibodies to the antigen in human sera," Proceedings of the National Academy of Sciences of the United States of America, vol. 78, no. 10, pp. 6476-6480, 1981.

[2] M. Yoshida, M. Seiki, K. Yamaguchi, and K. Takatsuki, "Monoclonal integration of human T-cell leukemia provirus in all primary tumors of adult T-cell leukemia suggests causative role of human T-cell leukemia virus in the disease," Proceedings of the National Academy of Sciences of the United States of America, vol. 81, no. 8, pp. 2534-2537, 1984.

[3] M. Osame, K. Usuku, S. Izumo, et al., "HTLV-I associated myelopathy, a new clinical entity," The Lancet, vol. 1, no. 8488, pp. 1031-1032, 1986.

[4] A. Gessain, F. Barin, J. C. Vernant, et al., "Antibodies to human T-lymphotropic virus type-I in patients with tropical spastic paraparesis," The Lancet, vol. 2, no. 8452, pp. 407-410, 1985.

[5] K. Verdonck, E. González, S. Van Dooren, A.-M. Vandamme, G. Vanham, and E. Gotuzzo, "Human T-lymphotropic virus 1: recent knowledge about an ancient infection," The Lancet Infectious Diseases, vol. 7, no. 4, pp. 266-281, 2007.

[6] G. de The and R. Bomford, "An HTLV-I vaccine: why, how, for whom?" AIDS Research and Human Retroviruses, vol. 9, no. 5, pp. 381-386, 1993.

[7] T. Uchiyama, "Human T cell leukemia virus type I (HTLV-I) and human diseases," Annual Review of Immunology, vol. 15, pp. 15-37, 1997.

[8] F. A. Proietti, A. B. F. Carneiro-Proietti, B. C. Catalan-Soares, and E. L. Murphy, "Global epidemiology of HTLV-I infection and associated diseases," Oncogene, vol. 24, no. 39, pp. 60586068, 2005.

[9] D. F. Roucoux, B. Wang, D. Smith, et al., "A prospective study of sexual transmission of human T lymphotropic virus (HTLV)-I and HTLV-II," Journal of Infectious Diseases, vol. 191, no. 9, pp. 1490-1497, 2005.

[10] S. Hino, K. Yamaguchi, S. Katamine, et al., "Mother-to-child transmission of human T-cell leukemia virus type-I," Japanese Journal of Cancer Research, vol. 76, no. 6, pp. 474-480, 1985.

[11] K. Kinoshita, T. Amagasaki, S. Hino, et al., "Milk-borne transmission of HTLV-I from carrier mothers to their children," Japanese Journal of Cancer Research, vol. 78, no. 7, pp. 674680, 1987.

[12] M. Nakagawa, K. Nakahara, Y. Maruyama, et al., "Therapeutic trials in 200 patients with HTLV-I-associated myelopathy/tropical spastic paraparesis," Journal of NeuroVirology, vol. 2, no. 5, pp. 345-355, 1996.

[13] M. Osame, R. Janssen, H. Kubota, et al., "Nationwide survey of HTLV-I-asscociated myelopathy in Japan: association with blood transfusion," Annals of Neurology, vol. 28, no. 1, pp. 50$56,1990$.

[14] M. Hisada, S. O. Stuver, A. Okayama, et al., "Persistent paradox of natural history of human $\mathrm{T}$ lymphotropic virus type I: parallel analyses of Japanese and Jamaican carriers," Journal of Infectious Diseases, vol. 190, no. 9, pp. 1605-1609, 2004.

[15] M. Nakagawa, S. Izumo, S. Ijichi, et al., "HTLV-I-associated myelopathy: analysis of 213 patients based on clinical features 
and laboratory findings," Journal of Neurovirology, vol. 1, no. 1, pp. 50-61, 1995.

[16] A. Kramer, E. M. Maloney, O. S. C. Morgan, et al., "Risk factors and cofactors for human T-cell lymphotropic virus type I (HTLV-I)-associated myelopathy/tropical spastic paraparesis (HAM/TSP) in Jamaica," American Journal of Epidemiology, vol. 142, no. 11, pp. 1212-1220, 1995.

[17] Y. Iwasaki, "Pathology of chronic myelopathy associated with HTLV-I infection (HAM/TSP)," Journal of the Neurological Sciences, vol. 96, no. 1, pp. 103-123, 1990.

[18] A. Yoshioka, G. Hirose, Y. Ueda, Y. Nishimura, and K. Sakai, "Neuropathological studies of the spinal cord in early stage HTLV-I-associated myelopathy (HAM)," Journal of Neurology Neurosurgery and Psychiatry, vol. 56, no. 9, pp. 1004-1007, 1993.

[19] S. Izumo, F. Umehara, and M. Osame, "HTLV-I-associated myelopathy," Neuropathology, vol. 20, supplement, pp. S65S68, 2000.

[20] S. Jacobson, "Immunopathogenesis of human T cell lymphotropic virus type I-associated neurologic disease," Journal of Infectious Diseases, vol. 186, supplement 2, pp. S187-S192, 2002.

[21] N. Takenouchi, Y. Yamano, K. Usuku, M. Osame, and S. Izumo, "Usefulness of proviral load measurement for monitoring of disease activity in individual patients with human T-lymphotropic virus type I-associated myelopathy/tropical spastic paraparesis," Journal of NeuroVirology, vol. 9, no. 1, pp. 29-35, 2003.

[22] M. Nagai, Y. Yamano, M. B. Brennan, C. A. Mora, and S. Jacobson, "Increased HTLV-I proviral load and preferential expansion of HTLV-I Tax-specific $\mathrm{CD}^{+} \mathrm{T}$ cells in cerebrospinal fluid from patients with HAM/TSP," Annals of Neurology, vol. 50, no. 6, pp. 807-812, 2001.

[23] D. Hayashi, R. Kubota, N. Takenouchi, et al., "Accumulation of human T-lymphotropic virus type I (HTLV-I)-infected cells in the cerebrospinal fluid during the exacerbation of HTLV-Iassociated myelopathy," Journal of NeuroVirology, vol. 14, no. 5, pp. 459-463, 2008.

[24] M. Nagai, K. Usuku, W. Matsumoto, et al., "Analysis of HTLV-I proviral load in $202 \mathrm{HAM} / \mathrm{TSP}$ patients and 243 asymptomatic HTLV-I carriers: high proviral load strongly predisposes to HAM/TSP," Journal of NeuroVirology, vol. 4, no. 6, pp. 586593, 1998.

[25] A. Manns, W. J. Miley, R. J. Wilks, et al., "Quantitative proviral DNA and antibody levels in the natural history of HTLV-I infection," Journal of Infectious Diseases, vol. 180, no. 5, pp. 1487-1493, 1999.

[26] V. Adaui, K. Verdonck, I. Best, et al., "SYBR green-based quantitation of human T-lymphotropic virus type 1 proviral load in Peruvian patients with neurological disease and asymptomatic carriers: influence of clinical status, sex, and familial relatedness," Journal of NeuroVirology, vol. 12, no. 6, pp. 456-465, 2006.

[27] A. H. Sabouri, M. Saito, K. Usuku, et al., "Differences in viral and host genetic risk factors for development of human T-cell lymphotropic virus type 1 (HTLV-1)-associated myelopathy/tropical spastic paraparesis between Iranian and Japanese HTLV-1-infected individuals," Journal of General Virology, vol. 86, no. 3, pp. 773-781, 2005.

[28] K. J. M. Jeffery, A. A. Siddiqui, M. Bunce, et al., "The influence of HLA class I alleles and heterozygosity on the outcome of human T cell lymphotropic virus type I infection," Journal of Immunology, vol. 165, no. 12, pp. 7278-7284, 2000.
[29] K. J. M. Jeffery, K. Usuku, S. E. Hall, et al., "HLA alleles determine human T-lymphotropic virus-I (HTLV-I) proviral load and the risk of HTLV-I-associated myelopathy," Proceedings of the National Academy of Sciences of the United States of America, vol. 96, no. 7, pp. 3848-3853, 1999.

[30] A. M. Vine, A. D. Witkover, A. L. Lloyd, et al., "Polygenic control of human T lymphotropic virus type I (HTLV-I) provirus load and the risk of HTLV-I-associated myelopathy/tropical spastic paraparesis," Journal of Infectious Diseases, vol. 186, no. 7, pp. 932-939, 2002.

[31] D. Kodama, M. Saito, W. Matsumoto, et al., "Longer dinucleotide repeat polymorphism in matrix metalloproteinase-9 (MMP-9) gene promoter which correlates with higher HTLVI Tax mediated transcriptional activity influences the risk of HTLV-I associated myelopathy/tropical spastic paraparesis (HAM/TSP)," Journal of Neuroimmunology, vol. 156, no. 1-2, pp. 188-194, 2004.

[32] A. H. Sabouri, M. Saito, A. L. Lloyd, et al., "Polymorphism in the interleukin-10 promoter affects both provirus load and the risk of human T lymphotropic virus type I-associated myelopathy/tropical spastic paraparesis," Journal of Infectious Diseases, vol. 190, no. 7, pp. 1279-1285, 2004.

[33] Y. Furukawa, M. Yamashita, K. Usuku, S. Izumo, M. Nakagawa, and M. Osame, "Phylogenetic subgroups of human $\mathrm{T}$ cell lymphotropic virus (HTLV) type I in the tax gene and their association with different risks for HTLV-I-associated myelopathy/tropical spastic paraparesis," Journal of Infectious Diseases, vol. 182, no. 5, pp. 1343-1349, 2000.

[34] J. Kira, M. Nakamura, T. Sawada, et al., "Antibody titers to HTLV-I-p $40^{\text {tax }}$ protein and gag-env hybrid protein in HTLV-Iassociated myelopathy/tropical spastic paraparesis: correlation with increased HTLV-I proviral DNA load," Journal of the Neurological Sciences, vol. 107, no. 1, pp. 98-104, 1992.

[35] S. Ishihara, A. Okayama, S. Stuver, et al., "Association of HTLV-I antibody profile of asymptomatic carriers with proviral DNA levels of peripheral blood mononuclear cells," Journal of Acquired Immune Deficiency Syndromes, vol. 7, no. 2, pp. 199-203, 1994.

[36] K. Nagasato, T. Nakamura, S. Shirabe, et al., "Presence of serum anti-human T-lymphotropic virus type I (HTLV-I) IgM antibodies means persistent active replication of HTLV-I in HTLV-I-associated myelopathy," Journal of the Neurological Sciences, vol. 103, no. 2, pp. 203-208, 1991.

[37] R. B. Lal, C.-Z. Giam, J. E. Coligan, and D. L. Rudolph, "Differential immune responsiveness to the immunodominant epitopes of regulatory proteins (tax and rex) in human $\mathrm{T}$ cell lymphotropic virus type I-associated myelopathy," Journal of Infectious Diseases, vol. 169, no. 3, pp. 496-503, 1994.

[38] M. C. Levin, S. M. Lee, F. Kalume, et al., "Autoimmunity due to molecular mimicry as a cause of neurological disease," Nature Medicine, vol. 8, no. 5, pp. 509-513, 2002.

[39] G. Dreyfuss, M. J. Matunis, S. Pinol-Roma, and C. G. Burd, "hnRNP proteins and the biogenesis of mRNA," Annual Review of Biochemistry, vol. 62, pp. 289-321, 1993.

[40] F. Yu, Y. Itoyama, K. Fujihara, and I. Goto, "Natural killer (NK) cells in HTLV-I-associated myelopathy/tropical spastic paraparesis-decrease in NK cell subset populations and activity in HTLV-I seropositive individuals," Journal of Neuroimmunology, vol. 33, pp. 121-128, 1991.

[41] M. Saito, V. M. Braud, P. Goon, et al., "Low frequency of CD94/NKG2A ${ }^{+} \mathrm{T}$ lymphocytes in patients with HTLV-1associated myelopathy/tropical spastic paraparesis, but not in asymptomatic carriers," Blood, vol. 102, no. 2, pp. 577-584, 2003. 
[42] K. Azakami, T. Sato, N. Araya, et al., "Severe loss of invariant NKT cells exhibiting anti-HTLV-1 activity in patients with HTLV-1-associated disorders," Blood, vol. 114, no. 15, pp. 3208-3215, 2009.

[43] L. C. Ndhlovu, J. E. Snyder-Cappione, K. I. Carvalho, et al., "Lower numbers of circulating natural killer T (NK T) cells in individuals with human T lymphotropic virus type 1 (HTLV1) associated neurological disease," Clinical and Experimental Immunology, vol. 158, no. 3, pp. 294-299, 2009.

[44] T. Matsuzaki, M. Saito, K. Usuku, et al., "A prospective uncontrolled trial of fermented milk drink containing viable Lactobacillus casei strain Shirota in the treatment of HTLV-1 associated myelopathy/tropical spastic paraparesis," Journal of the Neurological Sciences, vol. 237, no. 1-2, pp. 75-81, 2005.

[45] Y. Yamano, N. Takenouchi, H.-C. Li, et al., "Virus-induced dysfunction of $\mathrm{CD} 4{ }^{+} \mathrm{CD} 25^{+} \mathrm{T}$ cells in patients with HTLVI-associated neuroimmunological disease," Journal of Clinical Investigation, vol. 115, no. 5, pp. 1361-1368, 2005.

[46] S. Sakaguchi, M. Ono, R. Setoguchi, et al., "Foxp $3^{+} \mathrm{CD} 25^{+} \mathrm{CD} 4^{+}$natural regulatory $\mathrm{T}$ cells in dominant self-tolerance and autoimmune disease," Immunological Reviews, vol. 212, pp. 8-27, 2006.

[47] U. Oh, C. Grant, C. Griffith, K. Fugo, N. Takenouchi, and S. Jacobson, "Reduced Foxp3 protein expression is associated with inflammatory disease during human $\mathrm{T}$ lymphotropic virus type 1 infection," Journal of Infectious Diseases, vol. 193, no. 11, pp. 1557-1566, 2006.

[48] D. Hayashi, R. Kubota, N. Takenouchi, et al., "Reduced Foxp3 expression with increased cytomegalovirus-specific CTL in HTLV-I-associated myelopathy," Journal of Neuroimmunology, vol. 200, no. 1-2, pp. 115-124, 2008.

[49] F. Toulza, A. Heaps, Y. Tanaka, G. P. Taylor, and C. R. M. Bangham, "High frequency of $\mathrm{CD}^{+}{ }^{+} \mathrm{FoxP} 3^{+}$cells in HTLV1 infection: inverse correlation with HTLV-l-specific CTL response," Blood, vol. 111, no. 10, pp. 5047-5053, 2008.

[50] I. Best, G. López, K. Verdonck, et al., "IFN- $\gamma$ production in response to Tax 161-233, and frequency of $\mathrm{CD} 4^{+}$Foxp $3^{+}$ and Lin-HLA-DRhigh CD $123^{+}$cells, discriminate HAM/TSP patients from asymptomatic HTLV-1-carriers in a Peruvian population," Immunology, vol. 128, no. 1, part 2, pp. e777e786, 2009.

[51] J. Inoue, M. Seiki, T. Taniguchi, S. Tsuru, and M. Yoshida, "Induction of interleukin 2 receptor gene expression by $\mathrm{p} 40 \mathrm{x}$ encoded by human T-cell leukemia virus type 1," EMBO Journal, vol. 5, no. 11, pp. 2883-2888, 1986.

[52] B. Kitze, K. Usuku, Y. Yamano, et al., "Human $\mathrm{CD}^{+} \mathrm{T}$ lymphocytes recognize a highly conserved epitope of human T lymphotropic virus type 1 (HTLV-1) env gp21 restricted by HLA DRB1*0101," Clinical and Experimental Immunology, vol. 111, no. 2, pp. 278-285, 1998.

[53] P. K. C. Goon, T. Igakura, E. Hanon, et al., "Human T cell lymphotropic virus type I (HTLV-I)-specific CD4 ${ }^{+} \mathrm{T}$ cells: immunodominance hierarchy and preferential infection with HTLV-I," Journal of Immunology, vol. 172, no. 3, pp. 17351743, 2004.

[54] M. Kannagi, S. Harada, I. Maruyama, et al., "Predominant recognition of human T cell leukemia virus type I (HTLV-I) pX gene products by human $\mathrm{CD}^{+}$cytotoxic T cells directed against HTLV-I-infected cells," International Immunology, vol. 3, no. 8, pp. 761-767, 1991.

[55] S. Jacobson, H. Shida, D. E. McFarlin, A. S. Fauci, and S. Koenig, "Circulating $\mathrm{CD}^{+}$cytotoxic $\mathrm{T}$ lymphocytes specific for HTLV-I pX in patients with HTLV-I associated neurological disease," Nature, vol. 348, no. 6298, pp. 245-248, 1990.
[56] P. K. C. Goon, A. Biancardi, N. Fast, et al., "Human T cell lymphotropic virus (HTLV) type-1-specific $\mathrm{CD}^{+} \mathrm{T}$ cells: frequency and immunodominance hierarchy," Journal of Infectious Diseases, vol. 189, no. 12, pp. 2294-2298, 2004.

[57] H. Nose, R. Kubota, N. P. Seth, et al., "Ex vivo analysis of human $\mathrm{T}$ lymphotropic virus type 1 -specific $\mathrm{CD} 4^{+}$cells by use of a major histocompatibility complex class II tetramer composed of a neurological disease-susceptibility allele and its immunodominant peptide," Journal of Infectious Diseases, vol. 196, no. 12, pp. 1761-1772, 2007.

[58] P. K. C. Goon, E. Hanon, T. Igakura, et al., "High frequencies of Th1-type $\mathrm{CD}^{+}{ }^{+} \mathrm{T}$ cells specific to HTLV-1 Env and Tax proteins in patients with HTLV-1-associated myelopathy/tropical spastic paraparesis," Blood, vol. 99, no. 9, pp. 3335-3341, 2002.

[59] P. K. C. Goon, T. Igakura, E. Hanon, et al., "High circulating frequencies of tumor necrosis factor alpha- and interleukin2-secreting human T-lymphotropic virus type 1 (HTLV-1)specific $\mathrm{CD}^{+} \mathrm{T}$ cells in patients with HTLV-1-associated neurological disease," Journal of Virology, vol. 77, no. 17, pp. 9716-9722, 2003.

[60] M. Saito, G. P. Taylor, A. Saito, et al., "In vivo selection of Tcell receptor junctional region sequences by HLA-A2 human T-cell lymphotropic virus type 1 Tax11-19 peptide complexes," Journal of Virology, vol. 75, no. 2, pp. 1065-1071, 2001.

[61] M. Saito, I. Higuchi, A. Saito, et al., "Molecular analysis of $\mathrm{T}$ cell clonotypes in muscle-infiltrating lymphocytes from patients with human T lymphotropic virus type 1 polymyositis," Journal of Infectious Diseases, vol. 186, no. 9, pp. 12311241, 2002.

[62] C. R. M. Bangham, "The immune response to HTLV-I," Current Opinion in Immunology, vol. 12, no. 4, pp. 397-402, 2000.

[63] E. Hanon, S. Hall, G. P. Taylor, et al., "Abundant Tax protein expression in $\mathrm{CD}^{+} \mathrm{T}$ cells infected with human $\mathrm{T}$-cell lymphotropic virus type I (HTLV-I) is prevented by cytotoxic T lymphocytes," Blood, vol. 95, no. 4, pp. 1386-1392, 2000.

[64] T. F. Greten, J. E. Slansky, R. Kubota, et al., "Direct visualization of antigen-specific T cells: HTLV-1 Tax11-19-specific $\mathrm{CD}^{+} \mathrm{T}$ cells are activated in peripheral blood and accumulate in cerebrospinal fluid from HAM/TSP patients," Proceedings of the National Academy of Sciences of the United States of America, vol. 95, no. 13, pp. 7568-7573, 1998.

[65] M. Nagai, R. Kubota, T. F. Greten, J. P. Schneck, T. P. Leist, and S. Jacobson, "Increased activated human T cell lymphotropic virus type I (HTLV-I) Tax11-19-specific memory and effector $\mathrm{CD}^{+}$cells in patients with HTLV-Iassociated myelopathy/tropical spastic paraparesis: correlation with HTLV-I provirus load," Journal of Infectious Diseases, vol. 183, no. 2, pp. 197-205, 2001.

[66] R. Kubota, T. Kawanishi, H. Matsubara, A. Manns, and S. Jacobson, "Demonstration of human T lymphotropic virus type I (HTLV-I) tax-specific CD8 ${ }^{+}$lymphocytes directly in peripheral blood of HTLV-I-associated myelopathy/tropical spastic paraparesis patients by intracellular cytokine detection," Journal of Immunology, vol. 161, no. 1, pp. 482-488, 1998.

[67] A. H. Sabouri, K. Usuku, D. Hayashi, et al., "Impaired function of human T-lymphotropic virus type 1 (HTLV-1) specific $\mathrm{CD}^{+} \mathrm{T}$ cells in HTLV-1 associated neurologic disease," Blood, vol. 112, no. 6, pp. 2411-2420, 2008.

[68] S. E. Macatonia, J. K. Cruickshank, P. Rudge, and S. C. Knight, "Dendritic cells from patients with tropical spastic paraparesis 
are infected with HTLV-1 and stimulate autologous lymphocyte proliferation," AIDS Research and Human Retroviruses, vol. 8, no. 9, pp. 1699-1706, 1992.

[69] A. Ali, S. Patterson, K. Cruickshank, P. Rudge, A. G. Dalgleish, and S. C. Knight, "Dendritic cells infected in vitro with human T cell leukaemia/lymphoma virus type-1 (HTLV-1); enhanced lymphocytic proliferation and tropical spastic paraparesis," Clinical and Experimental Immunology, vol. 94, no. 1, pp. 3237, 1993.

[70] Y. Itoyama, S. Minato, J. Kira, et al., "Spontaneous proliferation of peripheral blood lymphocytes increased in patients with HTLV-I-associated myelopathy," Neurology, vol. 38, no. 8, pp. 1302-1307, 1988.

[71] S. Ijichi, N. Eiraku, M. Osame, et al., "In vitro modulation of lymphocyte proliferation by prednisolone and interferon- $\alpha$ in patients with HTLV-I-associated myelopathy (HAM)," Journal of Neuroimmunology, vol. 23, no. 2, pp. 175-178, 1989.

[72] M. Makino, M. Azuma, S.-I. Wakamatsu, et al., "Marked suppression of $\mathrm{T}$ cells by a benzothiophene derivative in patients with human T-lymphotropic virus type iassociated myelopathy/tropical spastic paraparesis," Clinical and Diagnostic Laboratory Immunology, vol. 6, no. 3, pp. 316-322, 1999.

[73] K. S. Jones, C. Petrow-Sadowski, Y. K. Huang, D. C. Bertolette, and F. W. Ruscetti, "Cell-free HTLV-1 infects dendritic cells leading to transmission and transformation of $\mathrm{CD} 4^{+} \mathrm{T}$ cells," Nature Medicine, vol. 14, no. 4, pp. 429-436, 2008.

[74] Y. Yamano, C. J. Cohen, N. Takenouchi, et al., "Increased expression of human T lymphocyte virus type I (HTLV-I) Tax11-19 peptide-human histocompatibility leukocyte antigen $\mathrm{A}^{*} 201$ complexes on $\mathrm{CD} 4^{+} \mathrm{CD} 25^{+} \mathrm{T}$ cells detected by peptide-specific, major histocompatibility complex-restricted antibodies in patients with HTLV-I-associated neurologic disease," Journal of Experimental Medicine, vol. 199, no. 10, pp. 1367-1377, 2004.

[75] S. L. Manuel, T. D. Schell, E. Acheampong, S. Rahman, Z. K. Khan, and P. Jain, "Presentation of human T cell leukemia virus type 1 (HTLV-1) Tax protein by dendritic cells: the underlying mechanism of HTLV-1-associated neuroinflammatory disease," Journal of Leukocyte Biology, vol. 86, no. 5, pp. 1205-1216, 2009.

[76] Y. Koyanagi, Y. Itoyama, N. Nakamura, et al., "In vivo infection of human T-cell leukemia virus type 1 in non-T cells," Virology, vol. 196, no. 1, pp. 25-33, 1993.

[77] C. Grant, K. Barmak, T. Alefantis, J. Yao, S. Jacobson, and B. Wigdahl, "Human T cell leukemia virus type I and neurologic disease: events in bone marrow, peripheral blood, and central nervous system during normal immune surveillance and neuroinflammation," Journal of Cellular Physiology, vol. 190, no. 2, pp. 133-159, 2002.

[78] M. Abe, F. Umehara, R. Kubota, T. Moritoyo, S. Izumo, and M. Osame, "Activation of macrophages/microglia with the calcium-binding proteins MRP14 and MRP8 is related to the lesional activities in the spinal cord of HTLV-I associated myelopathy," Journal of Neurology, vol. 246, no. 5, pp. 358-364, 1999.

[79] M. C. Levin, M. Krichavsky, R. J. Fox, et al., "Extensive latent retroviral infection in bone marrow of patients with HTLV-Iassociated neurologic disease," Blood, vol. 89, no. 1, pp. 346348, 1997.

[80] K. Nagafuji, M. Harada, T. Teshima, et al., "Hematopoietic progenitor cells from patients with adult T-cell leukemialymphoma are not infected with human T-cell leukemia virus type 1," Blood, vol. 82, no. 9, pp. 2823-2828, 1993. 


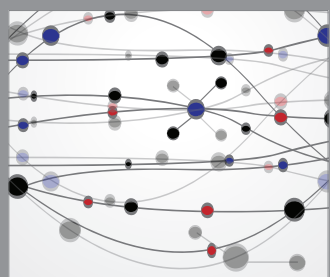

The Scientific World Journal
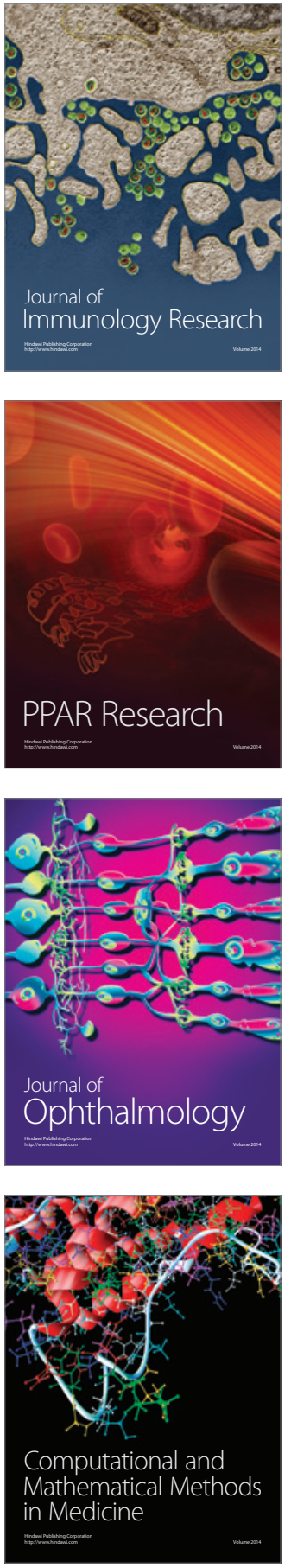

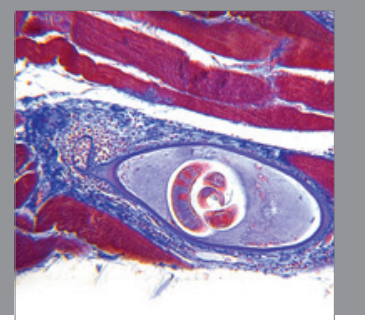

Gastroenterology

Research and Practice
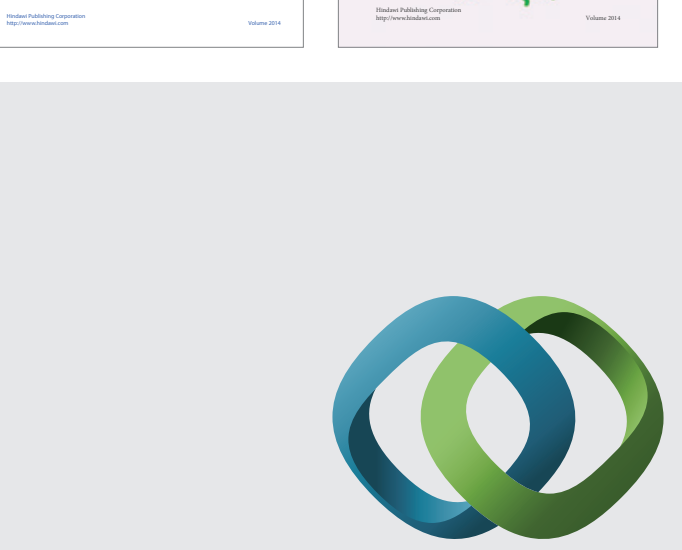

\section{Hindawi}

Submit your manuscripts at

http://www.hindawi.com
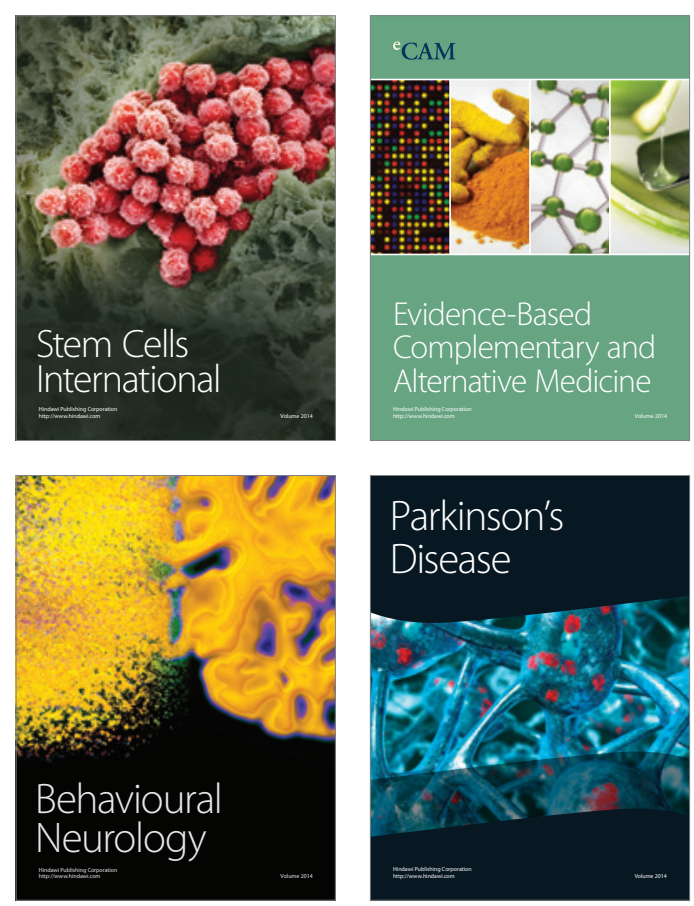

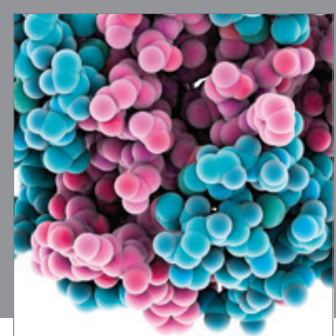

Journal of
Diabetes Research

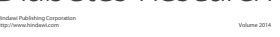

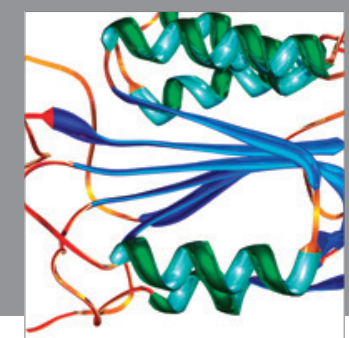

Disease Markers
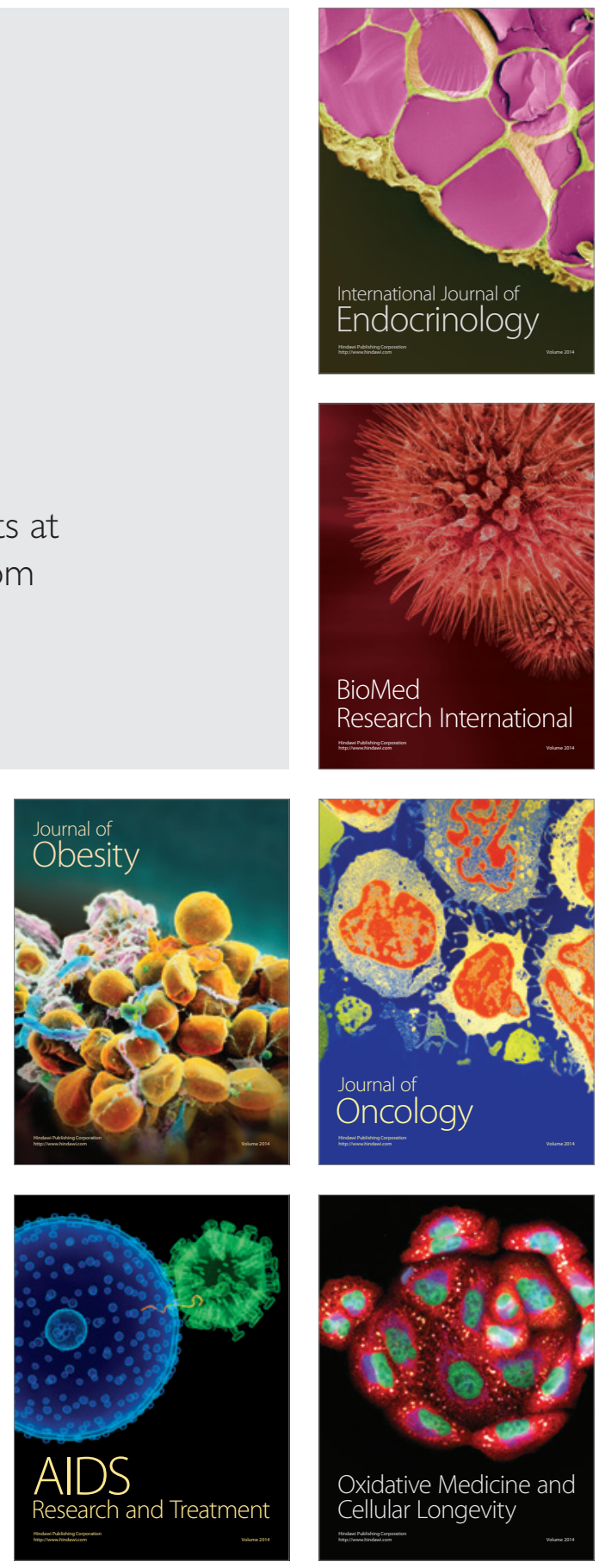